\title{
Concepções de Educação Ambiental de professores de biologia em formação nas universidades públicas federais do Recife
}

\section{Conceptions of environmental education of biology teachers-in training in the federal public universities of Recife}

\author{
Monica Lopes Folena Araújo ${ }^{1}$ \\ Tereza Luiza de França ${ }^{2}$
}

\begin{abstract}
RESUMO
A formação de professores é processo complexo e o papel de formar professores de biologia para atuar efetivamente com a Educação Ambiental (EA), em todos os níveis de ensino, impõe às universidades desafios e compromissos socioambientais complexos a serem assumidos. Tal afirmação leva-nos a perceber quão necessário é o diálogo universidade-educação ambiental na formação de profissionais que atuam em prol da sustentabilidade. Tendo isto como pressuposto, o presente trabalho teve por objetivo analisar concepções de EA de licenciandos em ciências biológicas das duas universidades públicas federais do Recife e refletir sobre as contribuições desses espaços formativos na formação de professores, pois as concepções de EA construídas na universidade têm relação direta com a prática docente exercida. Para tal, aplicamos questionários a estudantes de último período de ambos os cursos. Verificamos que há predomínio das concepções de EA como educação voltada ao meio ambiente e EA como educação para a sustentabilidade. Entretanto, encontramos também a concepção de EA como área da biologia, o que significa reduzi-la aos conceitos desta área do conhecimento e afastá-la da área educacional. Os resultados apontam para o compromisso acadêmico das universidades em garantir a EA na formação
\end{abstract}

1 Universidade Federal Rural de Pernambuco. Recife, Pernambuco, Brasil. Rua Dom Manoel de Medeiros, s/n, Dois Irmãos. CEP: 52171-900.

2 Universidade Federal de Pernambuco. Recife, Pernambuco, Brasil. Av. Jorn. Aníbal Fernandes, Cidade Universitária. CEP: 50740-560. 
de professores e para o necessário processo de discussão e reflexão ampla sobre questões socioambientais que visem o fortalecimento das instituições e, consequentemente, a formação de professores.

Palavras-chave: educação ambiental; formação de professores de biologia; universidades.

\begin{abstract}
Training teachers is a complex process and the role of educating biology teachers to work effectively with environmental education (EE), in all levels of education, imposes challenges and complex social and environmental commitments to be undertaken by the universities. This statement brings us to realize how necessary is the dialogue between the university and environmental education in the training of professionals to work towards sustainability. Taking this into consideration, the present work aimed at analyzing the concepts of EE of biological sciences undergraduate students from two public federal universities of Recife and reflecting on the contributions of these spaces in teacher training, because the concepts of EE built at the university are directly related to the practiced teaching. To this end, we applied questionnaires to students in the last period of both courses. We found that there is a predominance of conceptions of EE as education directed to the environment, and EE as education for sustainability. However, we also find the conception of EE as a biology sub-area, which means reducing it to concepts of this area of knowledge, and away from the area of education. Results point to the academic commitment of universities to ensure the EE in teacher education and to the necessary process of extensive discussion and reflection on social and environmental issues aimed at the strengthening of institutions and, consequently, of teachers education.
\end{abstract}

Keywords: environmental education; biology teachers education; universities.

\title{
O necessário diálogo universidade-educação ambiental na formação inicial de professores de biologia
}

A educação ambiental (EA) tem sido amplamente discutida nos últimos anos, em razão, entre outros fatores, dos relatórios do Painel Intergovernamental sobre Mudança Climática (IPCC), que divulgam a situação de desgaste do planeta Terra e apontam para uma série de medidas para a mitigação das mudanças 
climáticas globais. De acordo com os relatórios, há evidências que mudanças no modo de vida da população mundial podem contribuir para mitigar tais mudanças. Nesse sentido, pensamos que as universidades são locais de fomento e alicerce de discussões socioambientais que contribuem para a formação de cidadãos críticos, reflexivos e capazes de intervir nas realidades local, regional e global. Em outras palavras, um dos caminhos para a efetiva implementação da EA é a educação.

A educação comprometida com a realidade socioambiental constitui prática social que requer um conjunto de ações intencionais em prol da sustentabilidade; e uma de suas finalidades é contribuir para a humanização e emancipação do homem e para a formação de cidadãos críticos. Segundo Souza (2007), vamo-nos tornando humanos ou nos desumanizando no decorrer de nossa vida, conforme não só as nossas experiências, mas também as condições que construímos para a vida pessoal e na coletividade. De acordo com o referido autor, a humanização implica: pensar, emocionar-se e fazer no interior de determinadas relações sociais com a natureza. O ser humano é um ser de relações, e as estabelecidas com o meio natural e social não obedecem a padrões, elas estão em constante mudança, transformação.

Nessa perspectiva, Röhr (2006, p. 7) nos diz: “A intenção educacional é tornar o homem homem [...] de desenvolver nele o que tem de mais humano e que não é simplesmente resultado da sua maturação natural". Assim compreendida, a educação é ato de amor, vista como compromisso sensível do ato político de educar; ato de coragem, entendida como forma de resistência à educação bancária e à manutenção de um status quo. Para Freire (2000a), na educação não se pode temer o debate, a análise da realidade; não se pode fugir à discussão criadora, sob pena de tornar-se uma farsa.

Isso não significa que seja possível desenvolver todas as potencialidades humanas, mas aponta para a possibilidade da formação de sujeitos socioambientais, os quais seriam pessoas com jeito socioambiental de ser, novo estilo de vida, com modos próprios de pensar no e com o mundo e, principalmente, de pensar sobre si mesmos e sobre as relações com os outros neste mundo. Tal jeito de ser é a disposição em buscar responder aos dilemas socioambientais atuais mediante a transformação das relações entre sociedade e natureza.

Compreendemos que os maiores dilemas socioambientais na atualidade, ou seja, as maiores situações embaraçosas que vivenciamos, referem-se ao fato de decidir se o meio natural continuará sendo encarado como mercadoria para atender às exigências do mercado moderno ou se este será reconhecido como patrimônio da humanidade necessário à manutenção da vida; e também decidir as relações no mundo social e de produção. Isto implica a decisão de rever os padrões de consumo e a distribuição de bens na sociedade. A transformação das 
relações entre sociedade e natureza representa, neste sentido, passo importante para a sustentabilidade ambiental e social que cabe ser iniciada pela renovação da visão de mundo das pessoas, pois sociedade e natureza formam um único mundo que é, então, socioambiental.

Além das características já explicitadas, os sujeitos socioambientais apresentam postura ética de crítica à ordem social pautada na produtividade material baseada na exploração da natureza de forma utilitária e pragmática bem como na manutenção da desigualdade e da exclusão social e ambiental. Ademais, tais sujeitos se caracterizam como seres comprometidos com a integralidade da vida.

Frente ao exposto, cabe à universidade formar sujeitos socioambientais, pois ela é instituição que vive momentos de criação e recriação frente às necessidades sociais de cada época, de cada contexto histórico vivido. Nessa perspectiva, ela desempenha papel político-educacional que a torna vibrante, latente e revolucionária numa sistemática relação dialética de inconclusão e inacabamento com a sociedade.

Amaro Lins, ex-reitor da Universidade Federal de Pernambuco (UFPE), em painel apresentado durante o Seminário Educação no Brasil: Fator de Desenvolvimento Sustentável, organizado pela Academia Pernambucana de Ciência (APC) no ano de 2009, trouxe-nos à reflexão uma importante meta das universidades, entendidas como espaços de produção e socialização do conhecimento: a de contribuir para a discussão de temas prioritários ao desenvolvimento sustentável. Entre os temas citados pelo então reitor, destacamos: cidades sustentáveis, energia e sustentabilidade, empreendedorismo e tecnologias sociais, ecoeficiência e produção mais limpa, políticas públicas e sustentabilidade, ética e sustentabilidade e mudanças climáticas.

No mesmo evento, o senador e ex-Ministro da Educação Cristóvão Buarque apontou outras metas da universidade que tem por compromisso a sustentabilidade: ocupar-se dos problemas locais; ser universal; harmonizar-se com a natureza; criar um ambiente saudável; recuperar sonhos éticos, controlando a técnica e unindo-a à humanidade; redescobrir o valor da espiritualidade; e transgredir os conceitos e as práticas obsoletas, o que implica mudanças permanentes na sua estrutura, currículos e temas de estudo.

Tais mudanças tornam-se ainda mais necessárias quando pensamos que na universidade são formados professores que atuarão na educação básica e, portanto, terão papel preponderante na formação dos novos cidadãos brasileiros. Tardif (2008), ao refletir sobre o ensino como ofício moral, entende que a formação para o ensino não pode limitar-se a conhecimentos e competências; deve envolver também valores, compromissos normativos e convicções éticas, já que o professor trabalha "[...] com, sobre e para seres humanos em desenvolvimento e aprendizado. Trata-se, no sentido forte, de um trabalho de interações humanas" (p. 41). 
Para Imbernón (2006), na formação inicial ocorre a aquisição do conhecimento profissional básico, estágio durante o qual, segundo o referido autor, os professores atuam como um currículo oculto por meio de suas condutas socioculturais, políticas, profissionais, pessoais e valorativas explícitas ou implícitas. Leite (2004) com sua pesquisa sobre a formação de professores de ciências e biologia corrobora esse pensamento, ao descobrir que os ex-alunos de um curso de licenciatura esquecem os conteúdos de muitas disciplinas, mas mantêm a lembrança de atitudes e valores adquiridos no convívio e no exemplo de seus professores de graduação.

Todas as considerações expostas podem contribuir para a (re)criação da universidade na perspectiva da sustentabilidade socioambiental. Obviamente atingir as metas aqui trazidas demanda tempo e esforço por parte de todos que fazem a universidade. Entretanto, iniciar ou reiniciar o investimento em prol de uma universidade sustentável implica, em um primeiro momento, conhecê-la, fazer uma avaliação diagnóstica dos que a compõem em relação à EA.

Neste sentido, parece-nos que um bom caminho é mapear as concepções de professores, alunos e funcionários acerca da EA. A partir destas concepções, torna-se possível traçar metas e ações mais concretas a curto, médio e longo prazo. Imbuídas deste pensar, no presente trabalho nos dedicamos à análise das concepções de licenciandos em ciências biológicas das duas universidades públicas federais de Pernambuco e à reflexão sobre as contribuições desses espaços formativos na formação de professores. Tal estudo parece-nos importante porque há autores, como Guimarães (2005), que já constataram que professores de biologia e geografia são os que mais abordam a EA na escola. Ademais, conhecer as concepções de EA nos ajuda a identificar o que foi construído pelos licenciandos ao longo do curso de graduação em relação à EA.

\section{Lócus da pesquisa}

A presente pesquisa foi realizada no âmbito dos cursos de licenciatura em ciências biológicas oferecidos na sede das duas universidades públicas federais de Pernambuco. Em breve histórico do campo de pesquisa, percebemos que os cursos de licenciatura em ciências biológicas em ambas as instituições tiveram sua origem vinculada ao desmembramento ou mesmo à extinção de outros cursos, como é o caso do curso de ciências naturais. Trata-se de cursos que foram mudando suas identidades, suas fisionomias frente ao contexto social e 
à própria compreensão de ciências biológicas, que foi se consolidando como área de conhecimento específico ao longo do tempo.

O curso de licenciatura em ciências biológicas da UFPE foi criado no final da década de 1940 e era intitulado curso de história natural. Somente em 1979, com a regulamentação da profissão de biólogo pela Lei $\mathrm{n}^{0} 6.684$, o curso passou a denominar-se curso de ciências biológicas e, em 1994, foi realizada reforma curricular deste, criando-se dois perfis: licenciatura e bacharelado.

Estes tinham uma matriz curricular comum e as disciplinas específicas da licenciatura eram ofertadas no final do curso. Tal modelo de formação estendeu-se até 1996, quando os cursos de licenciatura e bacharelado foram desmembrados, passando a ter matrizes independentes. $\mathrm{O}$ atual perfil do curso de licenciatura é resultante de alterações implantadas no ano de 2010 por uma comissão de reforma do curso que visou adequá-lo às exigências das leis atuais que regulamentam a formação de professores para a educação básica, vincula-se ao centro de ciências biológicas e oferece 100 vagas anuais para o turno da noite (50 na primeira entrada e 50 na segunda). A duração mínima do curso é de oito semestres em 3.300 horas.

Em relação à EA, pudemos verificar, no relatório do perfil curricular do curso, disponibilizado no site da Instituição de Ensino Superior (IES), que ela não é ofertada na forma de componente curricular isolado. Localizamos os seguintes componentes curriculares eletivos que trazem a EA: conservação e educação ambiental; educação e avaliação ambiental; e natureza, sociedade e educação ambiental. Em relação a estas, constatamos que as respectivas ementas privilegiam a metodologia da EA, o que é aceito na Lei no 9.795, de 1999. À medida que fornecem meios à elaboração de propostas de trabalho em EA, tais componentes curriculares podem ser úteis à formação de professores de biologia.

Em 1975 foi criado, na Universidade Federal Rural de Pernambuco (UFRPE), o curso de licenciatura em ciências com as modalidades ou habilitações em biologia, física, matemática e química, sendo o departamento de biologia o responsável pela habilitação em biologia. Em 1989, houve o processo de separação do antigo currículo de ciências em quatro licenciaturas em diferentes departamentos. E, em 2006, o curso de licenciatura em ciências biológicas foi reformulado visando, assim como a UFPE, atender à legislação vigente. Ele oferece anualmente 80 vagas (40 na primeira entrada e 40 na segunda) e há turmas vespertinas e noturnas. A carga horária total do curso é de 2.900 horas e o período mínimo para integralização curricular é de oito semestres.

A EA é oferecida nesse curso como componente curricular eletivo e é responsabilidade da área de ecologia do departamento de biologia. Neste sentido, vemos a compreensão da EA como parte da ecologia, o que pode representar empecilhos e equívocos ao se trabalhar com a EA. 


\section{Atores da pesquisa e procedimentos metodológicos}

Participaram desta pesquisa 38 licenciandos de oitavo período da UFPE e 34 licenciandos do oitavo período da UFRPE, todos estudantes do curso de licenciatura em ciências biológicas. Selecionamo-los tendo por critérios: estar no último período e ter disponibilidade e desejo de colaborar com a pesquisa.

A construção dos dados foi feita através de questionários aplicados em abril de 2011 nas salas de aula das duas IES, pois o momento de aula em componentes curriculares obrigatórios foi o mais propício ao encontro dos licenciandos. Nos questionários havia apenas uma questão aberta: "O que é Educação Ambiental?". Deste modo, os licenciandos puderam responder livremente, explicitando suas concepções. Visando preservar a identidade dos estudantes, estes são identificados por flores de árvores frutíferas.

Para a análise dos dados seguimos as orientações de Bardin (1977). Então, organizamo-la em três fases: a pré-análise; a exploração do material e o tratamento dos resultados; e inferência e interpretação. Na primeira, efetuamos a leitura flutuante, "deixando-nos invadir por impressões e orientações" (BARDIN, 1977, p. 122).

Após tal leitura, procedemos à exploração cuidadosa e ao posterior tratamento dos resultados e interpretação. Recorremos ao que foi escrito livremente pelos estudantes, o que permitiu-nos perceber suas concepções de EA. Identificamos uma variedade de concepções nas duas IES, o que nos permite inferir que a EA é um campo amplo e no qual, muitas vezes, o expressar de concepções exige mais de um foco temático. Exatamente por este motivo, ressaltamos que os resultados ultrapassam a porcentagem de $100 \%$. Um mesmo licenciando atestou, por exemplo, que a EA é um ramo das ciências ambientais e que contribui para melhorar a natureza. Nesta resposta identificamos dois focos temáticos: a EA como ramo das ciências ambientais e a EA que contribuiu para melhorar a natureza.

\section{Resultados e discussão}

As respostas dadas pelos licenciandos da UFPE e da UFRPE estão explicitadas nas Figuras 1 e 2 respectivamente. Na primeira podemos verificar que nos licenciandos da UFPE há predomínio das concepções de EA como uma educação 
voltada ao meio ambiente $(52,63 \%)$, da EA como estudo de temas relacionados ao meio ambiente $(31,58 \%)$ e da EA como área que atua em defesa do meio ambiente, na sua preservação (31,58\%). Percebemos também a concepção de EA como conscientização $(21,1 \%)$, de EA como área que trabalha com processo de ensino/aprendizagem (15,79\%), de EA como ramo das ciências ambientais $(10,52 \%)$ e outras em menor porcentagem.

A EA encarada como educação voltada ao meio ambiente vem ao encontro do que autores como Carvalho (2008), Layrargues (2004) e Sauvé (2005) defendem; a EA seria composta por um substantivo que é "educação" e por um adjetivo que é "ambiental". A EA é a "educação voltada para o meio ambiente, que relaciona o dia a dia do ser humano com a postura, comportamento que possui diante da natureza e do meio ambiente" (Flor de Jambeiro). Percebemos, então, que a EA insere-se em contexto educacional, ideia esta que é reforçada ao encontramos a concepção de EA como aquela que trabalha com o processo de ensino-aprendizagem.

As concepções referentes ao estudo de temas relacionados ao meio ambiente e da EA como a que atua em defesa/preservação deste meio demonstram

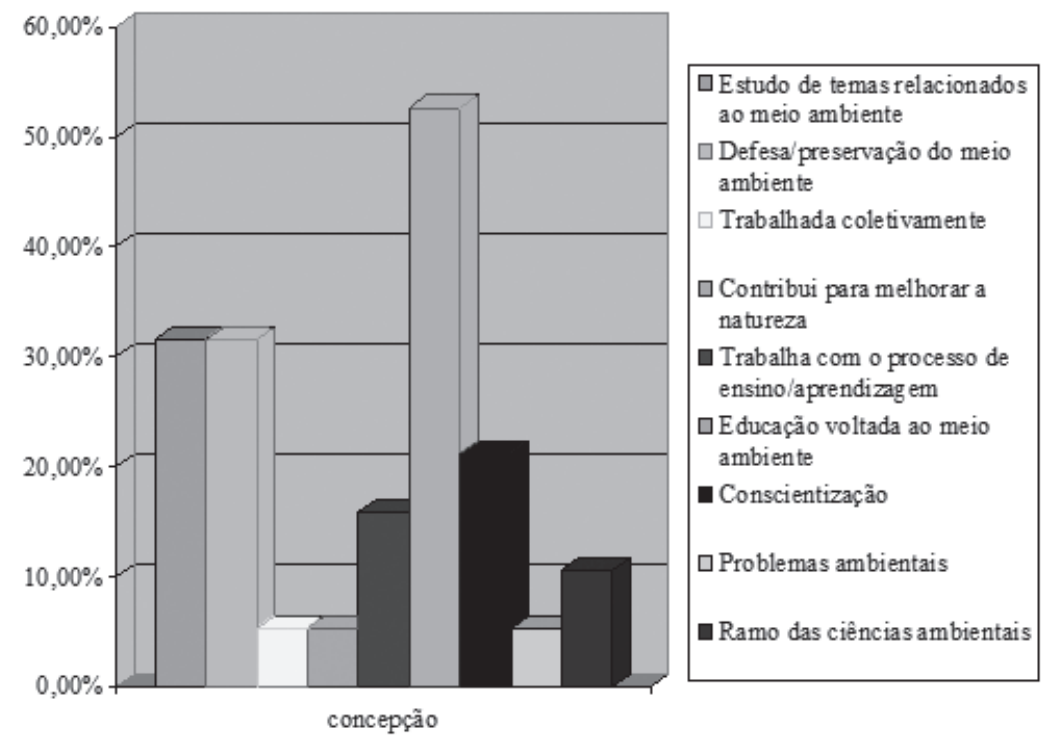

FIGURA 1 - CONCEPÇÕES DE EA DE LICENCIANDOS DA UFPE 
o caráter ativo da EA, pois esta não se faz apenas a partir da conscientização, que também foi uma concepção encontrada $(21,1 \%)$, mas também com estudos que possibilitam identificar mudanças em nosso planeta, fazer projeções futuras e pensar em possíveis formas de intervenção; um exemplo disso é o IPCC. Em relação à EA como conscientização a licencianda Flor de Ameixeira nos disse que a EA: "É a forma de conscientizar as pessoas sobre a importância do meio ambiente e conscientizar as pessoas a como conviver com ele da melhor forma possivel".

A concepção de EA como ramo das ciências ambientais possivelmente está atrelada ao fato de a UFPE ofertar o bacharelado em ciências biológicas na modalidade ciências ambientais e muitos dos componentes curriculares deste curso serem eletivos para a licenciatura. Esta concepção de EA pode reduzir a compreensão da EA trazida em documentos oficiais discutidos e criados no âmbito nacional e global, como o Tratado de educação ambiental para sociedades sustentáveis e responsabilidade global (FÓRUM GLOBAL, 1992).

Tal tratado resultou da Primeira Jornada de Educação Ambiental realizada no Rio de Janeiro, em 1992, durante o Fórum Global, evento paralelo à Segunda Conferência das Nações Unidas sobre Meio Ambiente e Desenvolvimento, a RIO-92 ou ECO-92. O referido tratado contou com a participação de professores que atuavam com crianças, jovens e adultos em diferentes regiões do mundo, entre elas: América Latina, América do Norte, Caribe, Europa, Ásia, Estados Árabes, África e Pacífico. Como destacam Sorrentino, Portugal e Viezzer (2009), além de servir de apoio à ação educativa, o tratado inspirou a criação de organizações da sociedade civil e redes de educação ambiental.

Alguns princípios constantes no aludido tratado podem inspirar e nortear o trabalho com a EA no Brasil: a educação é um direito de todos, somos todos aprendizes e educadores; a EA tem como base o pensamento crítico e inovador, por isso promove a transformação e a construção da sociedade; a EA ajuda a formar cidadãos com a consciência local e planetária; ela constitui um ato político; envolve perspectiva holística, enfocando a relação entre o ser humano, a natureza e o universo de forma interdisciplinar; a EA estimula a solidariedade, a igualdade e o respeito aos direitos humanos, valendo-se de estratégias democráticas e da interação entre as culturas; e ela ajuda a desenvolver a consciência ética sobre todas as formas de vida com as quais compartilhamos este planeta, a respeitar-lhes os ciclos vitais e a impor limites à exploração dessas formas de vida pelos seres humanos.

Porém, embora $10,52 \%$ dos licenciandos apresentem a concepção de EA como ramo das ciências ambientais, percebemos nas respostas que a EA tem como objetivo "orientar e reeducar ambientalmente as pessoas" (Flor de Goiabeira), o que insere a EA no campo educacional. 
A visão da EA como aquela que discute problemas ambientais leva-nos a perceber que podemos encontrar saídas, soluções para estes. Essas discussões perpassam áreas diferentes do conhecimento, pois problemas ambientais exigem análise na perspectiva complexa. Nesta direção, a concepção de EA como aquela que é trabalhada coletivamente $(5,26 \%)$ expressa a necessidade desse pensar complexo e coletivo na EA.

A concepção de EA como aquela que contribui para melhorar a natureza distancia-se da compreensão de EA em seu sentido mais amplo, pois esta concepção, já encontrada por Sato (2003), refere-se à visão da natureza como dádiva; alguns autores trazem esta concepção ao referir-se ao planeta Terra como mãe. Acreditamos que esta não seja a melhor maneira de ver nosso planeta, pois a ideia de mãe generosa que tudo concede definitivamente não corresponde às relações estabelecidas entre este e os seres humanos.

Os licenciandos da UFRPE também apresentam concepções diversas em relação à EA, tendo-se destacado a concepção de EA como educação para a sustentabilidade (41,18\%), EA como disciplina que nos ajuda a cuidar do meio ambiente $(35,29 \%)$ e EA como instrumento de sensibilização e conscientização $(29,41 \%)$. Todas as concepções relatadas encontram-se na Figura 2.

A concepção de EA como educação para a sustentabilidade encontra acolhida na obra Educar para a sustentabilidade, de autoria de Moacir Gadotti

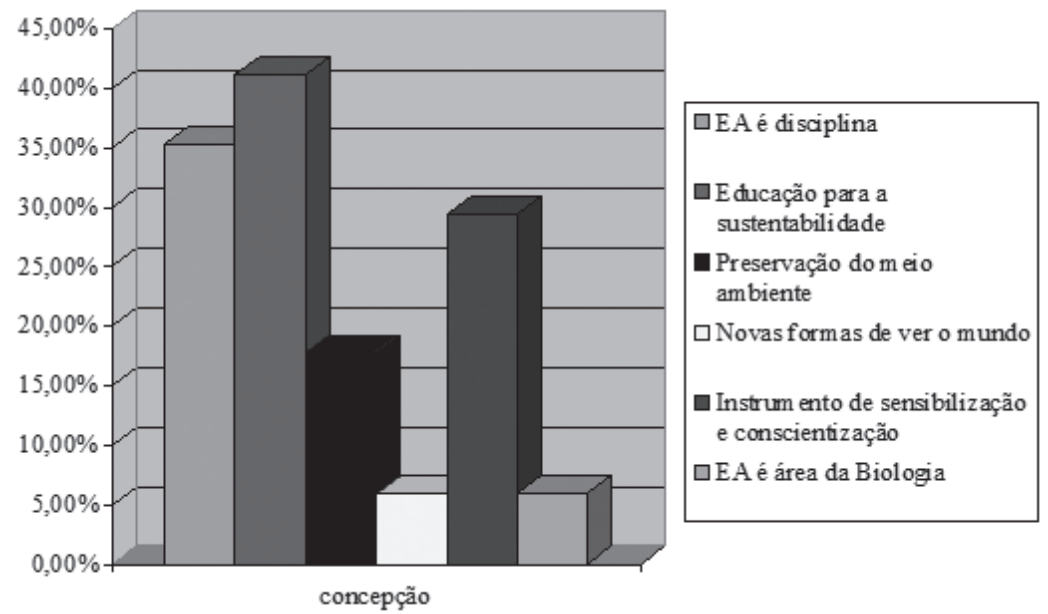

FIGURA 2 - CONCEPÇÕES DE EA DE LICENCIANDOS DA UFRPE 
(2008). Para o autor, a categoria sustentabilidade deve ser associada à planetaridade, pois a Terra precisa ser vista "como um novo paradigma" (p. 47). Assim, na concepção de EA como educação para a sustentabilidade, identificamos uma das identidades da EA já encontradas em estudo organizado pelo Ministério do Meio Ambiente (MMA): trata-se da ecopedagogia.

A ecopedagogia - considerada um movimento pedagógico (GADOTTI, 2000) de crítica à modernidade e de superação de padrões atuais de consumo propõe-se a ultrapassar o limite de ações pontuais no cotidiano, inserir a crítica à sociedade atual em diversos aspectos, projetar nova relação com a natureza fundamentada em outra relação entre os seres humanos e compreender tudo isso como um processo pedagógico e um movimento social. Para Ruscheinsky (2004a), a ecopedagogia

[...] leva em consideração os principais conflitos explicitados através do discurso sobre a ação política no intuito de veicular uma educação ambiental amparada na crítica, bem como a observação de eventos significativos pela sua visibilidade pública através dos quais se configura uma rede de organismos que se visualizam como atores sociais (RUSCHEINSKY, 2004a, p. 56).

Ela envolve movimento, energia e paixão que forja um trabalho para a educação comunitária e solidária, segundo destaca Ruscheinsky (2004b). Portanto, caracteriza-se decididamente como o inverso do modelo concorrencial, fratricida, excludente. Assim, consolida a ideia do futuro com base no desenvolvimento pautado na sustentabilidade, do ponto de vista social, ambiental, econômico e cultural. Em âmbito local, pode privilegiar projetos de geração de renda ecologicamente sustentáveis desde a produção ao consumo solidário.

Na concepção dos licenciandos de EA como educação para a sustentabilidade identificamos que: $41,18 \%$ referiam-se à EA como educação para a sustentabilidade ambiental; 5,88\% referiam-se à sustentabilidade social; 5,88\% referiam-se à sustentabilidade política; e 5,88\% destacaram a sustentabilidade ambiental, social, política e econômica. Percebemos, então, que a EA ainda é vista, primordialmente, como aquela que educa para a "sustentabilidade ambiental, para melhorarmos nossas relações com o planeta" (Flor de Pinha). Contudo, "a EA é a educação para a sustentabilidade ambiental, econômica, política e social; pois tudo está interligado" (Flor de Abiu).

A concepção de EA como disciplina que nos ajuda a cuidar do meio ambiente pode advir da própria vivência destes licenciandos, pois estes encontram 
a EA ofertada como componente curricular eletivo em suas matrizes curriculares na graduação. Além disso, a própria Secretaria de Educação do Estado também oferece a EA como disciplina na educação básica. Neste sentido, destacamos que ambas as esferas de ensino, educação superior e educação básica, necessitam adequar-se a Lei n $^{\circ}$ 9.795, de 1999, já que esta destaca que a EA não deve ser implantada como disciplina.

A EA como instrumento de sensibilização e conscientização nos adverte que "a EA precisa sensibilizar e conscientizar para conseguirmos mudança de atitudes e comportamentos em relação ao meio ambiente" (Flor de Limoeiro). Esta conscientização, se compreendida na perspectiva freireana, leva os seres humanos à consciência crítica e à intervenção no mundo representada pela "preservação do meio ambiente" (Flor de Jabuticabeira) e pela luta por condições socioambientais melhores para todos.

Dentre os licenciandos, 17,65\% afirmaram que a EA deve ou precisa cuidar da preservação do meio ambiente. Porém, identificamos que o meio ambiente é por eles compreendido não somente como natureza, mas também como seres humanos e as relações harmoniosas estabelecidas entre estes e a natureza. De acordo com Flor de Macieira, "preservar o meio ambiente é cuidar de nós mesmos e das relações que estabelecemos entre nós mesmos e com outras espécies". Neste sentido, embora os termos por eles utilizados tenham sido "preservação" ou "preservar", inferimos que se trata da "conservação" e que há equívoco nos termos utilizados nas respostas.

A concepção de EA como novas formas de ver o mundo (5,88\%) vem na perspectiva de que "não podemos mais olhar este mundo de forma simplificadora, pois a vida é complexa" (Flor de Pitombeira). Assim, o trabalho em EA na formação de professores traz consigo o trabalho com a complexidade, pois esta "amplia a capacidade de percepção, de visão e de compreensão não apenas do docente, mas também do discente [...]" (MORAES; NAVAS, 2010, p. 16). Os resultados deste estudo com os licenciandos demonstram que trabalhar com a EA é laborar com a complexidade e com concepções diversas de EA.

A EA como área da biologia, "já que os biólogos são mais bem preparados para atuar com as questões ambientais" (Flor de Pessegueiro), foi também uma concepção encontrada. A este respeito lembramos que pesquisas de Araújo (2008) demonstraram que os professores de biologia da educação básica encontram dificuldades para trabalhar com a EA nas escolas e tiveram formação inicial que pouco contribuiu para seu trabalho docente com a EA.

Além disso, a complexidade das questões ambientais e a importância destas para a manutenção da vida na Terra exigem a formação de profissionais aptos a trabalhar de forma inter e transdisciplinar. Considerar a EA como área da biologia significa reduzi-la aos conceitos desta área do conhecimento e afastá-la 
da área educacional, o que contraria o entendimento de teóricos que abordam esta temática, como Layrargues (2004) e Carvalho (2010).

\section{Considerações finais}

As concepções encontradas e analisadas neste trabalho permitiram identificar o que os licenciandos construíram em sua trajetória formativa nas universidades estudadas em relação à EA. Elas indicam que os licenciandos, em sua maioria, entendem a EA como educação voltada ao meio ambiente e também como educação para a sustentabilidade. Deste modo, suas concepções indicam a relação direta existente entre educação e EA, já que "ambiental" adjetiva o substantivo "educação".

Entretanto, também foram encontradas concepções de EA como ramo das ciências ambientais e de EA como área da Biologia; concepções estas que distanciam a EA da educação de forma mais ampla e que tendem a restringi-la a outra área do conhecimento, o que pode levá-los a exercer a docência com a concepção de que a EA é restrita à Biologia. Neste sentido, cabe-nos, nas considerações finais, refletir sobre as contribuições das universidades na formação de professores, pois as concepções construídas nestes espaços formativos têm relação direta com a prática docente exercida.

É incontestável a responsabilidade social das universidades na formação e na atuação profissional dos professores. Uma formação inicial que contemple princípios básicos da EA e metodologias diferenciadas de trabalho neste campo pode alicerçar a construção de concepções e, consequentemente, de práticas de EA na escola que contribuam para a formação de sujeitos socioambientais. Tal formação permite a percepção do caráter transversal, interdisciplinar e transdisciplinar da EA, o que possibilita a construção de concepções e práticas que ultrapassem os muros disciplinares e escolares.

Assim, pensamos que o papel de formar professores para atuar efetivamente com a EA, em todos os níveis de ensino, impõe às instituições formadoras uma política que contemple a humanização e a criticidade como eixos norteadores alimentados pela compreensão de elas serem agentes de transformação para o desenvolvimento sustentável.

Esse compromisso, tomando por base princípios do desenvolvimento sustentável, tem por objetivo reverter a perda de recursos ambientais e contribuir para outras ações concretas a fim de manter as condições objetivas de existência para as pessoas e outras espécies, tendo em conta a habitabilidade, a boniteza da vida e o respeito a esta em todas as suas formas. 
Boniteza, neste trabalho, tem o significado de vida com amorosidade, bem querer, solidariedade, estética, ética, alegria, esperança e rigorosa formação. Segundo nos diz Freire (2002), decência e boniteza andam de mãos dadas. Temos diferentes possibilidades para o nosso futuro comum, mas o ser humano tem o compromisso de "comparecer à História não apenas como objeto, mas também como sujeito" (FREIRE, 2000b, p. 119). Ele intervém no e com o mundo e deixa suas marcas de sujeito histórico. O compromisso da universidade é ajudar o ser humano nesse sentido, evitando que ele deixe apenas pegadas ecológicas, como se fosse puro objeto.

\section{REFERÊNCIAS}

ARAÚJO, M. L. F. Tecendo conexões entre a trajetória formativa de professores de biologia e a prática docente a partir da educação ambiental. 192f. Dissertação (Mestrado em Ensino das Ciências) - Universidade Federal Rural de Pernambuco, Recife, 2008.

BARDIN, L. Análise de conteúdo. Lisboa: 70, 1977.

BRASIL. Lei no 6.684, de 3 de setembro de 1979. Regulamenta as profissões de Biólogo e de Biomédico, cria o Conselho Federal e os Conselhos Regionais de Biologia e Biomedicina, e dá outras providências. Diário Oficial da União, Brasília, DF, 4 set. 1979.

. Lei no 9.795, de 27 de abril de 1999. Dispõe sobre a Educação Ambiental, institui a Política Nacional de Educação Ambiental e dá outras providências. Diário Oficial da União, Brasília, DF, 28 abr. 1999.

BUARQUE, C. O modelo de universidade do século XXI. In: SEMINÁRIO EDUCAÇÃO NO BRASIL: Fator de Desenvolvimento Sustentável, 2009, Recife. Anais... Pernambuco: Academia Pernambucana de Ciências, 2009.

CARVALHO, I. C. M. Educação ambiental: a formação do sujeito ecológico. 2. ed. São Paulo: Cortez, 2008.

CARVALHO, L. M. de. A pesquisa no campo da formação e do trabalho docente relacionado com a temática ambiental. In: DALBEN, A.; DINIZ, J.; LEAL, L.; SANTOS, L. Convergências e tensões no campo da formação e do trabalho docente: educação ambiental, educação em ciências, educação em espaços não-escolares e educação matemática (textos selecionados do XV ENDIPE). Belo Horizonte: Autêntica, 2010. p. 67-88.

FREIRE, P. Educação como prática de liberdade. 24. ed. Rio de Janeiro: Paz e Terra, 2000a. 
. Pedagogia da indignação: cartas pedagógicas e outros escritos. São Paulo: UNESP, $2000 \mathrm{~b}$.

. Pedagogia da autonomia: saberes necessários à prática educativa. 22. ed. Rio de Janeiro: Paz e Terra, 2002.

GADOTTI, M. Perspectivas atuais da educação. Porto Alegre: Artes Médicas, 2000.

. Educar para a sustentabilidade: uma contribuição à Década da Educação para o Desenvolvimento Sustentável. São Paulo: Instituto Paulo Freire, 2008.

FÓRUM GLOBAL DAS ORGANIZAÇÕES NÃO GOVERNAMENTAIS. Tratado de educação ambiental para sociedades sustentáveis e responsabilidade global. In: CONFERÊNCIA DAS NAÇÕES UNIDAS SOBRE O MEIO AMBIENTE E O DESENVOLVIMENTO, 1992, Rio de Janeiro. Tratados... Rio de Janeiro, 1992.

GUIMARÃES, M. A formação de educadores ambientais. 2. ed. Campinas: Papirus, 2005. IMBERNÓN, F. Formação docente e profissional: formar-se para a mudança. 6. ed. São Paulo: Cortez, 2006.

LAYRARGUES, P. P. (Org.). Identidades da educação ambiental brasileira. Brasília, DF: Ministério do Meio Ambiente, 2004.

LEITE, M. A. Formação docente: ciências e biologia. Bauru: EDUSC, 2004.

LINS, A. H. P. Contribuições das universidades para o desenvolvimento sustentável. In: SEMINÁRIO EDUCAÇÃO NO BRASIL: Fator de Desenvolvimento Sustentável, 2009, Recife. Anais... Pernambuco: Academia Pernambucana de Ciências, 2009.

MORAES, M. C.; NAVAS, J. M. B. (Orgs.). Complexidade e transdisciplinaridade em educação: teoria e prática docente. Rio de Janeiro: Wak, 2010.

RÖHR, F. Reflexões em torno de um possível objeto epistêmico próprio da educação. Pro-Posições, Campinas, v. 18, n. 1, p. 1-20, jan./abr. 2006.

RUSCHEINSKY, A. Atores sociais e meio ambiente: a mediação da ecopedagogia. In: LAYRARGUES, P. P. (Org.). Identidades da educação ambiental brasileira. Brasília, DF: Ministério do Meio Ambiente, 2004a. p. 51-63.

(Org.). Sustentabilidade: uma paixão em movimento. Porto Alegre: Sulina, 2004b.

SATO, M. Educação ambiental. São Carlos: RIMA, 2003.

SAUVÉ, L. Uma cartografia das correntes em educação ambiental. In: SATO, M.; CARVALHO, I. C. M. Educação ambiental: pesquisa e desafios. Porto Alegre: Artmed, 2005. p. 17-44.

SORRENTINO, M; PORTUGAL, S.; VIEZZER, M. A educação de jovens e adultos à luz do Tratado de Educação Ambiental para Sociedades Sustentáveis e Responsabilidade Global. La Piragua - Revista Latinoamericana de Educación y Política, Juarez, v. 2, n. 29, p. 93-108, maio 2009. 
SOUZA, J. F. E a educação popular: ?? Que?? Uma pedagogia para fundamentar a educação, inclusive escolar, necessária ao povo brasileiro. Recife: Bagaço, 2007.

TARDIF, M. Princípios para guiar a aplicação dos programas de formação inicial para o ensino. In: EGGERT, E. et al. Trajetórias e processos de ensinar e aprender: didática e formação de professores (textos selecionados do XIV ENDIPE). Porto Alegre: EDIPUCRS, 2008. p. 17-46.

Texto recebido em 27 de agosto de 2012.

Texto aprovado em 08 de agosto de 2013. 